\title{
Behaviour of structural stainless steel cross-sections under combined loading - Part I: Experimental study
}

\author{
Ou Zhao ${ }^{\text {a }}$, Barbara Rossi ${ }^{\mathrm{b}}$, Leroy Gardner $^{\mathrm{a}}$, Ben Young ${ }^{\mathrm{c}}$ \\ ${ }^{\text {a }}$ Imperial College London, Dept. of Civil and Environmental Engineering, London, UK \\ ${ }^{\mathrm{b}}$ KU Leuven, Dept. of Civil Engineering, Belgium \\ ${ }^{\mathrm{c}}$ The University of Hong Kong, Dept. of Civil Engineering, Hong Kong, China
}

\begin{abstract}
Stainless steel has been gaining increasing use in a variety of engineering applications due to its unique combination of mechanical properties, durability and aesthetics. Significant progress in the development of structural design guidance has been made in recent years, underpinned by sound research. However, an area that has remained relatively unexplored is that of combined loading. Testing and analysis of stainless steel cross-sections under combined axial load and bending is therefore the subject of the present paper and the companion paper [1]. The experimental programme covers both austenitic and lean duplex stainless steels, and five cross-section sizes including three Square Hollow Sections (SHS) and two Rectangular Hollow Sections (RHS). In total, five stub column tests, five four-point bending tests, 20 uniaxial bending plus compression tests and four biaxial bending plus compression tests were carried out to investigate the cross-sectional behaviour of tubular stainless steel sections under combined bending and compression. The initial loading eccentricities for the combined loading tests were varied to provide a wide range of proportions of bending moment to axial load. For each type of test, the test setup, experimental procedures, full experimental load-deformation histories and key test results are
\end{abstract}


reported in detail. All the experimental results are then employed in the companion paper [1] for the validation of finite element (FE) models, by means of which a series of parametric results is generated, and for the assessment of the design provisions given in EN 1993-1-4 [2] and SEI/ASCE-8 [3]. Improved design rules for stainless steel cross-sections under combined loading are also sought through extension of the deformation-based Continuous Strength Method (CSM).

\section{Introduction}

Cold-formed stainless steel hollow sections are becoming an attractive choice in a range of structural applications since they combine the durability advantages of stainless steel with the aesthetic appeal, structural efficiency and potential for concrete-infilling [4-8] of closed tubular profiles. The tested cross-sections were formed from austenitic and lean duplex stainless steels. Extensive experimental and numerical studies have been previously conducted on tubular sections of these grades under compression and bending, acting in isolation. Previous researchers [9-15] have carried out stub column tests on different crosssection classes to study the cross-sectional compressive response and local buckling behaviour. Three-point bending tests [16-18] and four-point bending tests [12,19-21] have been performed to investigate the flexural response and rotation capacity of stainless steel beams under a moment gradient and constant moment, respectively. On the basis of the findings, revised slenderness limits for cross-section classification [22] and new effective width formulae for slender sections [13] have been proposed. Theofanous et al. [23] conducted two-span continuous beam tests to enable the influence of moment redistribution within statically indeterminate beams to be examined. As highlighted by previous researchers, the general codified approach of limiting the design stress to the $0.2 \%$ proof stress, and 
ignoring the pronounced strain hardening exhibited by stainless steels can lead to greatly underestimated cross-sectional resistances. To address this shortcoming, Gardner [24] and Ashraf et al. [25] proposed a deformation-based design approach called the Continuous Strength Method (CSM) to allow a rational exploitation of strain hardening. The latest developments to the CSM for stainless steel were presented by Afshan and Gardner [26], where substantially improved predictions of capacity over current design methods were demonstrated. However, to date, limited research has been conducted into the cross-sectional behaviour of stainless steel tubular sections under combined axial load and bending moment, and this is therefore the focus of the present investigation.

An experimental programme was undertaken at the University of Liege and Imperial College London, aiming at investigating the cross-sectional interaction response of stainless steel elements under combined loading. Five stub column tests and five four-point bending tests were performed firstly to obtain the basic cross-sectional response characteristics under isolated loading cases. 20 uniaxial bending plus compression tests were then conducted to study the cross-sectional behaviour under uniaxial combined loading conditions. Finally, the influence of biaxial bending on the cross-sectional compression capacity was investigated by conducting four biaxial bending plus compression tests. The test setup, experimental procedures and key test results for each type of test are reported in detail herein. In the companion paper [1], a numerical modelling programme is described, in which the experimental response is initially replicated to validate the FE models and then parametric studies are carried out to generate further structural performance data. These data are analysed and discussed in combination with the test results, and used to evaluate the accuracy of existing design rules in EN 1993-1-6 [2] and SEI/ASCE-8 [3] and to develop more efficient design rules for stainless steel cross-sections under combined loading conditions. 


\section{Experimental investigation}

\subsection{Introduction}

An experimental study covering austenitic and lean duplex stainless steels and a range of hollow section sizes including both SHS and RHS was conducted at the University of Liege and Imperial College London, with the aim of investigating the cross-sectional behaviour of tubular sections under combined loading conditions. Overall, the laboratory testing programme comprised material testing, geometric imperfection measurements, five stub column tests, five four-point bending tests, 20 uniaxial bending plus compression tests and four biaxial bending plus compression tests. Five cross-section sizes were employed, which were SHS $100 \times 100 \times 5$, SHS $120 \times 120 \times 5$, RHS $150 \times 100 \times 6$, and RHS $150 \times 100 \times 8$ of austenitic grade (EN 1.4301, 1.4571, 1.4307 and 1.4404, respectively) and SHS 150×150×8 of lean duplex grade (EN 1.4162). The chemical compositions for each section, as provided by the mill certificates, are presented in the Table 1 . The testing apparatus, experimental procedures and test results for each type of test are reported in detail in the following sections.

\subsection{Material testing}

A comprehensive description of the material testing carried out on the sections studied herein was given by Afshan et al. [27], while only a brief summary is provided in the present paper. All tensile coupon tests were conducted using a Zwick/Roell Z100 kN electromechanical testing machine, in which a set of end-clamps were utilized to allow appropriate gripping of the coupons in the machine jaws with flat surface clamps used for the flat coupons and Vshaped clamps employed for the corner coupons. For each section size, two flat coupons and 
two corner coupons were tested. Two flat coupons were cut from the centrelines of the faces adjacent to the welded face whilst two corner coupons were taken from the curved corner regions opposite to the weld, as shown in Fig. 1. All the coupon tests were performed under strain-control according to the requirements of EN ISO 6892-1 [28]. For each cross-section, the average measured flat and corner material properties, obtained from coupons cut from the complete profiles, are reported in Table 2 and Table 3, respectively, while the tensile properties of the coil material from the mill certificates are listed in Table 4 , where $\sigma_{0.2}$ is the $0.2 \%$ proof stress, $\sigma_{1.0}$ is the $1.0 \%$ proof stress, $\sigma_{u}$ is the ultimate tensile stress, $\varepsilon_{u}$ is the strain at the ultimate tensile stress, $\varepsilon_{f}$ is the plastic strain at fracture measured over the standard gauge length, and $n$ and $n_{0.2,1.0}^{\prime}$ are the strain hardening exponents used in the compound Ramberg-Osgood (R-O) material model [29-32].

\subsection{Geometric imperfection measurements}

Geometric imperfections are an inevitable and important characteristic of thin-walled structures, which influence structural performance. Owing to the absence of global buckling phenomena in the present study, only local imperfections were measured. The procedures and test setup for imperfection measurements were similar to those suggested by Schafer and Peköz [33] in which a Linear Variable Displacement Transducer (LVDT) was affixed to the head of the milling machine with specimens lying on the moving machine base, as shown in Fig. 2. For each specimen, imperfection measurements were conducted along the centrelines of all the four faces. To eliminate the effect of end flaring [34] due to the release of residual stress and the influence of the welds, all the imperfection measurements were taken over the central $50 \%$ of the member length, at $2 \mathrm{~mm}$ intervals. The maximum imperfection amplitude for each face was defined as the maximum deviation from a linear trend line fitted to the data 
set. The largest value of the measured maximum deviations from four faces was taken as the initial local imperfection amplitude of the specimen. Measured geometric imperfection distributions for the four faces of a typical beam specimen are shown in Fig. 3. Tables 5, 7, 9 and 11 report the local imperfection amplitudes for the specimens tested under pure compression, four-point bending, uniaxial bending plus compression and biaxial bending plus compression, respectively.

\subsection{Stub column tests}

For each section size, a concentric stub column test was performed for the determination of deformation and load-carrying capacities under pure compression. The nominal length of each stub column specimen fell within the range between three times the width of the widest plate element and 20 times the least radius of gyration of the gross cross-section, as recommended in EN 1993-1-3 [35]; this length is deemed short enough to avoid global flexural buckling, but still long enough to contain a representative pattern of local geometric imperfection and residual stress. The member length, geometric dimensions and imperfection amplitude for each specimen were measured prior to stub column testing and are reported in Table 5, where $L$ is the member length, $B$ and $H$ are the outer section width and depth, respectively, $t$ is the material thickness, $r_{i}$ is the internal corner radius, $A$ is the cross-section area and $\omega_{0}$ is the measured maximum local imperfection.

The ends of each stub column were milled flat and square to allow accurate seating of the ends on the parallel platens of the test machine, which ensured a uniform load distribution on the specimen during testing. The parallel end platens were fixed against rotations and twist about any axis to achieve fixed boundary conditions. All the tests were performed under 
displacement-control at a constant speed of $0.15 \mathrm{~mm} / \mathrm{min}$. Fig. 4 depicts the stub column test setup, in which the instrumentation consists of four LVDTs to measure the end shortening, four linear electrical resistance strain gauges attached to each specimen at a distance of four times the thickness from the corners at mid-height to determine the corresponding longitudinal strains, and a load cell to record the applied load. Each test was continued into the post-ultimate range to enable the falling path to be captured. All data, including the applied load, strain gauge readings and LVDT values were recorded at $1 \mathrm{~s}$ intervals, using acquisition equipment ScanWin.

As indicated in previous studies [10,36], the end shortening measurements from LVDTs include not only the end shortening of the specimen but also the elastic deformation of the end platens of the test machine. Based on the strain gauge readings, the true end shortening values were obtained following the procedure recommended in [36]. Fig. 5 depicts the modified true load-end shortening curves for all the specimens, while a summary of key test results, including the ultimate load $N_{u}$, the ratio of $N_{u} / A \sigma_{0.2}$ and the corresponding end shortening $\delta_{u}$ at ultimate load, is given in Table 6. Note that the high $N_{u} / A \sigma_{0.2}$ ratios are associated with the assumption that the yield load $\left(A \sigma_{0.2}\right)$ is the limiting capacity of the cross-section, which neglects the influence of strain hardening. All specimens failed by inelastic local buckling. Typical deformed specimens, for SHS $100 \times 100 \times 5-1 \mathrm{~A}$ and RHS 150×100×6-3A, are depicted in Figs. 6 and 7, respectively.

\subsection{Four-point bending tests}

In total, five symmetric four-point bending tests were carried out to investigate the flexural performance and rotation capacity of the stainless steel sections under constant bending 
moment. Owing to the closed nature of the tested sections and the relatively short span lengths, there was no possibility of lateral torsional buckling; hence only local geometric imperfections were measured, as previously described. Table 7 lists the measured geometric properties, initial local geometric imperfection amplitude $\omega_{0}$, total member length $L_{t}$, flexural span length $L_{f}$, and the length between loading points $L_{m}$ for each specimen. The total member length $L_{t}$ was equal to the flexural span length $L_{f}$ between steel roller supports plus two equal overhanging lengths of $100 \mathrm{~mm}$ beyond the centrelines of supports.

As shown in Fig. 8, the simply-supported beams were loaded symmetrically at two points through a spreader beam. Steel transfer plates were introduced between the specimen and the two loading points to distribute the load and wooden blocks were inserted into the tube at the loading points to prevent web crippling. A similar arrangement has been successfully employed in previous studies [12,37]. Strain gauges were attached to the top and bottom flanges of the test specimens at a distance of $5 \mathrm{~mm}$ from the mid-span to avoid contact with the string potentiometer, which was placed at mid-span to measure the vertical deflection. Two additional string potentiometers were employed at the loading points to measure vertical deflections at these locations. Displacement-control was again used with a constant speed of $1 \mathrm{~mm} / \mathrm{min}$ for all the tests. For each experiment, the specimen cross-section was orientated such that the face containing the weld was always the bottom (tension) flange, to achieve symmetry. Finally, load, vertical deflections and strain were recorded by a data acquisition system DATASCAN at a rate of $1 \mathrm{~s}$.

Fig. 9 depicts the failed beam specimens, all of which exhibited local buckling of the compression flange and upper portion of the webs within the constant moment region. The normalised moment-curvature curves $M / M_{p l}-\kappa / \kappa_{p l}$ for all tests are shown in Fig. 10, 
where $M_{p l}$ is the cross-sectional plastic bending resistance, $\kappa_{p l}$ is the elastic curvature corresponding to $M_{p l}$ and $\kappa$ is the curvature determined from Eq. (1) [38], in which $D_{M}$ is the vertical deflection at mid-span, $D_{L}$ is the average vertical deflection at the two loading points and $L_{m}$ is the length of the constant moment region (i.e. the distance between the loading points). Table 8 reports the key experimental results, including the ultimate test moment $M_{u}$, the ratios of test ultimate moment to the elastic and plastic moment capacities $\left(M_{u} / M_{e l}\right.$ and $\left.M_{u} / M_{p l}\right)$ and the rotation capacity $R$, which was evaluated according to Eq.

(2). The high ratios of test ultimate moment to the elastic and plastic moment capacities can be attributed to the assumption of elastic perfectly plastic material behaviour in the definition of $M_{e l}$ and $M_{p l}$, which does not match closely to the rounded and strain hardening material response of stainless steel.

$$
\begin{aligned}
& \kappa=\frac{8\left(D_{M}-D_{L}\right)}{4\left(D_{M}-D_{L}\right)^{2}+L_{m}^{2}} \\
& R=\frac{\kappa_{u}}{\kappa_{p l}}-1
\end{aligned}
$$

where $\kappa_{u}$ is the curvature at which the falling branch of the moment-curvature curve reaches $M_{p l}$.

\subsection{Combined loading tests}

In total, 20 uniaxial bending plus compression tests and four biaxial bending plus compression tests were carried out, with the aim of investigating the cross-sectional behaviour of stainless steel tubular sections under combined loading conditions. The test programme was arranged as follows: For each of the five studied cross-section sizes, four 
uniaxial bending plus compression tests, with varying initial load eccentricities, were conducted. For the RHS $150 \times 100 \times 6$ specimens, major axis bending plus compression tests were performed, whereas for the RHS $150 \times 100 \times 8$ specimens, the bending was about the minor axis. In addition to the uniaxial bending plus compression tests, four biaxial bending plus compression tests were also carried out on the SHS $100 \times 100 \times 5$ specimens.

For each test specimen, geometric dimensions were measured, before $25 \mathrm{~mm}$ thick end plates were welded to the member ends. The nominal length of each combined loading specimen was similar to that of the corresponding stub column specimen. The measured geometric properties and imperfection amplitudes, together with the specimen IDs and initial loading eccentricities are summarised in Tables 9 and 11 for specimens under uniaxial bending plus compression and biaxial bending plus compression, respectively.

The combined loading tests were conducted using an AMSLER $5000 \mathrm{kN}$ hydraulic testing machine with hemispherical bearings at both ends providing pin-ended conditions in any direction. The centrelines of the hydraulic actuator, the top hemispherical bearing and the bottom hemispherical bearing coincided with each other, which ensured no resultant bending moment acting on the hemispherical bearings. The common point of the concurrent forces imposed by the hydraulic actuator to the hemispherical bearing was located at the centroid of the flat face of the hemispherical bearing (see Fig. 11(a)), and therefore the effective length $L_{e}$ in each test was equal to the specimen length plus the thickness of the two welded end plates. Fig. 11(a) and Fig. 11(b) provide a schematic diagram and photograph of the test setup. Specimens were eccentrically bolted to the hemispherical bearings of the test machine, thus resulting in the end sections of the specimens free to rotate about both principal axes. However, the twist rotation was restrained by an anchor device, as shown in Fig. 11(a) and 
Fig. 11(b). The initial loading eccentricities for the combined loading tests were varied to generate a range of proportions of bending moment to axial load.

During the experiments, the applied eccentric load initially induces uniform bending moment and single curvature along the member length. However, as discussed by Fujimoto et al. [39] and Gardner et al. [40], with increasing applied load, the lateral deformation of the specimen generates additional second order bending moments. Therefore, in order to evaluate the second order bending moments, the lateral deflections in both principal directions were measured by means of two string potentiometers, which were affixed to the specimens at mid-height. Two inclinometers located at both ends of the test specimens were used for the determination of end rotations. Finally, four strain gauges were attached to the extreme fibres of the cross-sections at mid-height to capture the longitudinal strains, which would be used to derive the actual initial loading eccentricity for each combined loading test, as discussed later. A data acquisition system ScanWin was utilized to record the applied load, lateral deflections, end rotations and longitudinal strains at one-second intervals.

Initial loading eccentricity is one of the key test parameters and has a strong influence on the beam-column cross-sectional interaction behaviour. It is also important in the numerical modelling in order to accurately replicate the experimental response and predict the ultimate load. Prior to testing, each specimen was eccentrically bolted to the hemispherical bearings at a specific nominal eccentricity. The test eccentricities were then measured directly and also calculated from the strain gauges readings, following the procedure described below. The measured and calculated eccentricities were in good agreement, and the calculated values are reported in Tables 10 and 12 for uniaxial bending plus compression tests and for biaxial bending plus compression tests, respectively. For each axis of bending, the strain due to the 
bending moment $\varepsilon_{m}$ is equal to $\left(\varepsilon_{\max }-\varepsilon_{\min }\right) / 2$, where $\varepsilon_{\max }$ and $\varepsilon_{\min }$ are the strain values of the maximum compressive fibre and the maximum tensile (or the minimum compressive, in some cases) fibre, respectively. The actual bending moment at mid-height can be derived from $M=E I \kappa$, where $E$ and $I$ are the weighted average (based on the areas of flat and corner parts) Young's modulus and the second moment of area about the axis of bending, respectively, and $\kappa$ is the curvature at mid-height equal to $\varepsilon_{m} / 0.5 D$, in which $D$ is the relevant outer dimension of the cross-section. The actual initial eccentricity is then evaluated as $e_{0}=(E I \kappa / N-\Delta)$, where $N$ is the applied load and $\Delta$ is the lateral deflection at midheight, as measured by the string potentiometer. The final expression for calculating the initial eccentricity about each axis of buckling is defined by Eq. (3)

$e_{0}=\frac{E I\left(\varepsilon_{\max }-\varepsilon_{\min }\right)}{D N}-\Delta$

Note that the initial eccentricity was determined as the average calculated value during the early stage of loading, where the material behaviour was elastic.

Table 10 summarises the key test results including the failure load $N_{u}$, the actual initial loading eccentricity, referred to as the first order eccentricity $e_{0}$, the generated lateral deflection at failure load, referred to as the second order eccentricity $e^{\prime}$, the failure moment $M_{u}=N_{u}\left(e_{0}+e^{\prime}\right)$ and the corresponding end rotation at failure $\phi_{u}$ for the uniaxial bending plus compression tests. The experimental results for the biaxial bending plus compression tests are listed in Table 12, in which the initial loading eccentricities and the corresponding lateral deflections, failure moments and end rotations about both principal axes are reported.

The experimental load-end rotation curves for each cross-section under uniaxial bending plus compression with varying initial eccentricities are shown in Figs. 12(a)-12(e), whist those 
under biaxial bending plus compression are depicted in Figs.13(a)-13(d). In terms of failure modes, significant local buckling was observed at mid-height for all test specimens; typical failure modes for the SHS and RHS specimens under uniaxial bending plus compression are displayed in Fig. 14, while a representative failure mode from a biaxial bending plus compression test is illustrated in Fig. 15, showing local buckling about both principal axes.

\section{Conclusions}

A series of experiments performed to investigate the cross-sectional response of stainless steel tubular sections under combined loading has been reported. A total of 34 cross-section tests were carried out. Five cross-section sizes including three Square Hollow Sections (SHS) and two Rectangular Hollow Sections (RHS) of different material grades were employed. The experimental programme included material testing, geometric imperfection measurements, five stub column tests, five four-point bending tests, 20 uniaxial bending plus compression tests and four biaxial bending plus compression tests. Various initial loading eccentricities were considered to vary the ratio of bending moment to applied axial load. For the RHS, the cross-sectional behaviour under both major and minor axis combined loading conditions was examined. The test setup and experimental procedures for each type of test have been fully described. Full load-deformation histories have been presented for all test types. Key test results including the ultimate load and the corresponding deformation parameters at ultimate load have also been tabulated. All experimental results are utilized in the companion paper [1] for validation of the numerical models, and evaluation and development of suitable procedures for stainless steel cross-sections under combined loading. 


\section{Acknowledgements}

The authors are grateful to Stalatube Oy, Finland for supplying test specimens and to Joint $\mathrm{PhD}$ Scholarship from Imperial College London for financial support. They would also like to thank Max Verstraete from the University of Liege and Gordon Herbert from Imperial College London for their contribution to the experimental investigations.

\section{Reference}

[1] Zhao O, Rossi B, Gardner L, Young B. Behaviour of stainless steel cross-sections under combined loading - Part II: Numerical modelling and design approach.

[2] EN 1993-1-4. Eurocode 3: Design of steel structures - Part 1.4: General rules Supplementary rules for stainless steels. Brussels: European Committee for Standardization (CEN); 2006.

[3] SEI/ASCE 8-02. Specification for the design of cold-formed stainless steel structural members. Reston: American Society of Civil Engineers (ASCE); 2002.

[4] Young B, Ellobody E. Experimental investigation of concrete-filled cold-formed high strength stainless steel tube columns. Journal of Constructional Steel Research, 2006;62(5):484-92.

[5] Lam D, Gardner L. Structural design of stainless steel concrete filled columns. Journal of Constructional Steel Research, 2008;64(11):1275-82. 
[6] Hassanein MF. Numerical modelling of concrete-filled lean duplex slender stainless steel tubular stub columns. Journal of Constructional Steel Research, 2010;66(8):1057-68.

[7] Uy B, Tao Z, Han LH. Behaviour of short and slender concrete-filled stainless steel tubular columns. Journal of Constructional Steel Research, 2011;67(3):360-78.

[8] Han LH, Chen F, Liao FY, Tao Z, Uy B. Fire performance of concrete filled stainless steel tubular columns. Engineering Structures, 2013;56:165-81.

[9] Rasmussen K, Hancock G. Design of cold-formed stainless steel tubular members. I: Columns. Journal of Structural Engineering (ASCE), 1993;119(8):2349-67.

[10] Gardner L, Nethercot D. Experiments on stainless steel hollow sections - Part 1: Material and cross-sectional behaviour. Journal of Constructional Steel Research, 2004;60(9):1291-318.

[11] Young B, Lui WM. Behavior of cold-formed high strength stainless steel sections. Journal of Structural Engineering (ASCE), 2005;131(11):1738-45.

[12] Gardner L, Talja A, Baddoo N. Structural design of high-strength austenitic stainless steel. Thin-Walled Structures, 2006;44(5):517-28.

[13] Theofanous M, Gardner L. Testing and numerical modelling of lean duplex stainless steel hollow section columns. Engineering Structures, 2009;31(12):3047-58.

[14] Huang Y, Young B. Material properties of cold-formed lean duplex stainless steel sections. Thin-Walled Structures, 2012;54(7):72-81. 
[15] Shu G, Zheng B, Shen X. Experimental and theoretical study on the behaviour of coldformed stainless steel stub columns. International Journal of Steel Structures, 2013;13(1)14153.

[16] Gardner L, Nethercot D. Experiments on stainless steel hollow sections - Part 2: Member behaviour of columns and beams. Journal of Constructional Steel Research, 2004;60(9):1319-32.

[17] Real E, Mirambell E. Flexural behaviour of stainless steel beams. Engineering Structures, 2005;27(10):1465-75.

[18] Theofanous M, Gardner L. Experimental and numerical studies of lean duplex stainless steel beams. Journal of Constructional Steel Research, 2010;66(6):816-25.

[19] Rasmussen K, Hancock G. Design of cold-formed stainless steel tubular members. II: Beams. Journal of Structural Engineering (ASCE), 1993;119(8):2368-86.

[20] Zhou F, Young B. Tests of cold-formed stainless steel tubular flexural members. ThinWalled Structures, 2005;43(9):1325-37.

[21] Huang Y, Young B. Experimental and numerical investigation of cold-formed lean duplex stainless steel flexural members. Thin-Walled Structures, 2013;73(19):216-28.

[22] Gardner L, Theofanous M. Discrete and continuous treatment of local buckling in stainless steel elements. Journal of Constructional Steel Research, 2008;64(11):1207-16.

[23] Theofanous M, Saliba N, Zhao O, Gardner, L. Ultimate response of stainless steel continuous beams. Thin-Walled Structures, In press. 
[24] Gardner L. A new approach to structural stainless steel design. PhD Thesis. UK: Imperial College London; 2002.

[25] Ashraf M, Gardner L, Nethercot D. Structural stainless steel design: resistance based on deformation capacity. Journal of Structural Engineering (ASCE), 2008;134(3):402-11.

[26] Afshan S, Gardner L. The continuous strength method for structural stainless steel design. Thin-Walled Structures, 2013;68(4):42-49.

[27] Afshan S, Rossi B, Gardner L. Strength enhancements in cold-formed structural sections - Part I: Material testing, Journal of Constructional Steel Research, 2013;83(16):177-88.

[28] EN ISO 6892-1. Metallic materials - tensile testing - Part 1: Method of test at room temperature. Brussels: European Committee for Standardization (CEN); 2009.

[29] Ramberg W, Osgood WR. Description of stress-strain curves by three parameters. Technical note No 902, Washington DC: National advisory committee for aeronautics; 1943.

[30] Hill HN. Determination of stress-strain relations from offset yield strength values. Technical note No 927, Washington DC: National advisory committee for aeronautics; 1944.

[31] Mirambell E, Real E. On the calculation of deflections in structural stainless steel beams: An experimental and numerical investigation. Journal of Constructional Steel Research, 2000;54(1):109-33.

[32] Gardner L, Ashraf M. Structural design for non-linear metallic materials. Engineering Structures, 2006;28(6):926-34. 
[33] Schafer BW, Peköz T. Computational modelling of cold-formed steel: Characterizing geometric imperfections and residual stresses. Journal of Constructional Steel Research, 1998;47(3):193-210.

[34] Cruise RB, Gardner L. Measurement and prediction of geometric imperfections in structural stainless steel members. Structural Engineering and Mechanics, 2006;24(1):63-89.

[35] EN 1993-1-3. Eurocode 3: Design of steel structures - Part 1.3: General rules Supplementary rules for cold-formed members and sheeting. Brussels: European Committee for Standardization (CEN); 2006.

[36] Centre for Advanced Structural Engineering. Compression tests of stainless steel tubular columns. Investigation report S770. University of Sydney; 1990.

[37] Afshan S, Gardner L. Experimental study of cold-formed ferritic stainless steel hollow sections. Journal of Structural Engineering (ASCE), 2013;139(5):717-28.

[38] Chan TM, Gardner L. Bending strength of hot-rolled elliptical hollow sections. Journal of Constructional Steel Research, 2008;64(9):971-86.

[39] Fujimoto T, Mukai A, Nishiyama I, Sakino K. Behaviour of eccentrically loaded concrete-filled steel tubular columns. Journal of Structural Engineering (ASCE), 2004;130(2):203-212.

[40] Gardner L, Chan TM, Abela JM. Structural behaviour of elliptical hollow sections under combined compression and uniaxial bending. Advanced Steel Construction, 2011;7(1):86112. 
Table 1 Chemical compositions stated in the mill certificates.

\begin{tabular}{|c|c|c|c|c|c|c|c|c|c|c|c|c|}
\hline Cross-section & Grade & $\begin{array}{c}\mathrm{C} \\
(\%)\end{array}$ & $\begin{array}{c}\mathrm{Si} \\
(\%)\end{array}$ & $\begin{array}{l}\mathrm{Mn} \\
(\%)\end{array}$ & $\begin{array}{c}\mathrm{P} \\
(\%)\end{array}$ & $\begin{array}{c}\mathrm{S} \\
(\%)\end{array}$ & $\begin{array}{l}\mathrm{Cr} \\
(\%)\end{array}$ & $\begin{array}{l}\mathrm{Ni} \\
(\%)\end{array}$ & $\begin{array}{c}\mathrm{N} \\
(\%)\end{array}$ & $\begin{array}{l}\text { Mo } \\
(\%)\end{array}$ & $\begin{array}{l}\mathrm{Cu} \\
(\%)\end{array}$ & $\begin{array}{l}\mathrm{Nb} \\
(\%)\end{array}$ \\
\hline SHS 100 & 1.4301 & 0.044 & 0.35 & 1.34 & 0.029 & 0.001 & 18.24 & 8.12 & 0.058 & 0.21 & - & - \\
\hline SHS $120 \times 120 \times 5$ & 1.4571 & 0.040 & 0.39 & 1.22 & 0.027 & 0.001 & 16.70 & 10.7 & 0.010 & 2.06 & - & - \\
\hline RHS $150 \times 100 \times 6$ & 1.4307 & 0.023 & 0.39 & 1.76 & 0.029 & 0.001 & 18.20 & 8.10 & 0.043 & - & - & - \\
\hline RHS $150 \times 100 \times 8$ & 1.4404 & 0.022 & 0.49 & 1.74 & 0.032 & 0.002 & 17.00 & 10.00 & 0.042 & 2.04 & - & - \\
\hline SHS $150 \times 150 \times 8$ & 1.4162 & 0.029 & 0.74 & 4.97 & 0.020 & 0.001 & 21.68 & 1.59 & 0.215 & 0.32 & 0.34 & - \\
\hline
\end{tabular}

Table 2 Average measured tensile flat material properties.

\begin{tabular}{ccccccccc}
\hline Cross-section & $E$ & $\sigma_{0.2}$ & $\sigma_{1.0}$ & $\sigma_{u}$ & $\varepsilon_{u}$ & $\varepsilon_{f}$ & \multicolumn{2}{c}{ R-O coefficient } \\
\cline { 7 - 9 } & $\left(\mathrm{N} / \mathrm{mm}^{2}\right)$ & $\left(\mathrm{N} / \mathrm{mm}^{2}\right)$ & $\left(\mathrm{N} / \mathrm{mm}^{2}\right)$ & $\left(\mathrm{N} / \mathrm{mm}^{2}\right)$ & $(\%)$ & $(\%)$ & $n$ & $n_{0.2,1.0}^{\prime}$ \\
\hline SHS $100 \times 100 \times 5$ & 193400 & 434 & 492 & 683 & 48 & 61 & 4.7 & 2.9 \\
SHS $120 \times 120 \times 5$ & 192550 & 343 & 391 & 605 & 44 & 61 & 6.7 & 2.4 \\
RHS $150 \times 100 \times 6$ & 193250 & 341 & 385 & 642 & 48 & 60 & 6.6 & 2.2 \\
RHS $150 \times 100 \times 8$ & 196109 & 335 & 384 & 608 & 45 & 66 & 5.9 & 2.6 \\
SHS $150 \times 150 \times 8$ & 198700 & 519 & 578 & 728 & 28 & 52 & 5.3 & 2.8 \\
\hline
\end{tabular}

Table 3 Average measured tensile corner material properties.

\begin{tabular}{ccccccccc}
\hline Cross-section & $E$ & $\sigma_{0.2}$ & $\sigma_{1.0}$ & $\sigma_{u}$ & $\varepsilon_{u}$ & $\varepsilon_{f}$ & \multicolumn{2}{c}{ R-O coefficient } \\
\cline { 7 - 10 } & $\left(\mathrm{N} / \mathrm{mm}^{2}\right)$ & $\left(\mathrm{N} / \mathrm{mm}^{2}\right)$ & $\left(\mathrm{N} / \mathrm{mm}^{2}\right)$ & $\left(\mathrm{N} / \mathrm{mm}^{2}\right)$ & $(\%)$ & $(\%)$ & $n$ & $n_{0.2,1.0}^{\prime}$ \\
\hline SHS $100 \times 100 \times 5$ & 192200 & 599 & 773 & 810 & 24 & 33 & 3.6 & 19.6 \\
SHS $120 \times 120 \times 5$ & 192900 & 526 & 601 & 687 & 28 & 47 & 10.8 & 3.0 \\
RHS $150 \times 100 \times 6$ & 189750 & 607 & 660 & 808 & 33 & 44 & 8.7 & 3.0 \\
RHS $150 \times 100 \times 8$ & 200700 & 559 & 622 & 725 & 28 & 51 & 4.8 & 3.9 \\
SHS $150 \times 150 \times 8$ & 206750 & 831 & 906 & 920 & 3 & 21 & 8.9 & 6.1 \\
\hline
\end{tabular}

Table 4 Mechanical properties stated in the mill certificates.

\begin{tabular}{ccccc}
\hline Cross-section & $\begin{array}{c}\sigma_{0.2, \text { mill }} \\
\left(\mathrm{N} / \mathrm{mm}^{2}\right)\end{array}$ & $\begin{array}{c}\sigma_{1.0, \text { mill }} \\
\left(\mathrm{N} / \mathrm{mm}^{2}\right)\end{array}$ & $\begin{array}{c}\sigma_{u, \text { mill }} \\
\left(\mathrm{N} / \mathrm{mm}^{2}\right)\end{array}$ & $\begin{array}{c}\varepsilon_{f} \\
(\%)\end{array}$ \\
\hline SHS $100 \times 100 \times 5$ & 310 & - & 670 & 51 \\
SHS $120 \times 120 \times 5$ & 268 & 315 & 584 & 53 \\
RHS $150 \times 100 \times 6$ & 284 & 328 & 603 & 56 \\
RHS $150 \times 100 \times 8$ & 285 & 336 & 590 & 53 \\
SHS $150 \times 150 \times 8$ & 561 & 605 & 747 & - \\
\hline
\end{tabular}


Table 5 Measured dimensions of stub column specimens.

\begin{tabular}{ccccccccc}
\hline Cross-section & Specimen ID & $\begin{array}{c}L \\
(\mathrm{~mm})\end{array}$ & $\begin{array}{c}H \\
(\mathrm{~mm})\end{array}$ & $\begin{array}{c}B \\
(\mathrm{~mm})\end{array}$ & $\begin{array}{c}t \\
(\mathrm{~mm})\end{array}$ & $\begin{array}{c}r_{i} \\
(\mathrm{~mm})\end{array}$ & $\begin{array}{c}A \\
\left(\mathrm{~mm}^{2}\right)\end{array}$ & $\begin{array}{c}\omega_{0} \\
(\mathrm{~mm})\end{array}$ \\
\hline SHS $100 \times 100 \times 5$ & 1A & 349.9 & 100.0 & 99.9 & 4.65 & 2.08 & 1736.9 & 0.015 \\
SHS $120 \times 120 \times 5$ & 2A & 399.9 & 120.3 & 120.1 & 4.65 & 5.79 & 2084.8 & 0.039 \\
RHS $150 \times 100 \times 6$ & 3A & 450.1 & 150.6 & 100.0 & 5.87 & 7.05 & 2703.6 & 0.043 \\
RHS $150 \times 100 \times 8$ & 4A & 450.0 & 150.1 & 100.2 & 7.75 & 9.65 & 3459.4 & 0.028 \\
SHS $150 \times 150 \times 8$ & 5A & 449.8 & 150.4 & 150.0 & 8.04 & 11.17 & 4362.8 & 0.015 \\
\hline
\end{tabular}

Table 6 Summary of test results for stub columns.

\begin{tabular}{|c|c|c|c|c|}
\hline Cross-section & Specimen ID & $\begin{array}{l}\text { Ultimate load } N_{u} \\
(\mathrm{kN})\end{array}$ & $\begin{array}{l}\text { End shortening at ultimate load } \delta_{u} \\
(\mathrm{~mm})\end{array}$ & $N_{u} / A \sigma_{0.2}$ \\
\hline SHS $100 \times 100 \times 5$ & $1 \mathrm{~A}$ & 1057.0 & 5.07 & 1.27 \\
\hline SHS $120 \times 120 \times 5$ & $2 \mathrm{~A}$ & 928.4 & 3.58 & 1.13 \\
\hline RHS $150 \times 100 \times 6$ & $3 \mathrm{~A}$ & 1323.7 & 7.06 & 1.14 \\
\hline RHS $150 \times 100 \times 8$ & $4 \mathrm{~A}$ & 1825.1 & 12.78 & 1.20 \\
\hline SHS $150 \times 150 \times 8$ & $5 \mathrm{~A}$ & 3257.9 & 10.27 & 1.15 \\
\hline
\end{tabular}

Table 7 Measured dimensions of beam specimens.

\begin{tabular}{|c|c|c|c|c|c|c|c|c|c|c|}
\hline Cross-section & Specimen ID & Axis of bending & $\begin{array}{c}L_{t} \\
(\mathrm{~mm})\end{array}$ & $\begin{array}{c}L_{f} \\
(\mathrm{~mm})\end{array}$ & $\begin{array}{c}L_{m} \\
(\mathrm{~mm})\end{array}$ & $\begin{array}{c}H \\
(\mathrm{~mm})\end{array}$ & $\begin{array}{c}B \\
(\mathrm{~mm})\end{array}$ & $\begin{array}{c}t \\
(\mathrm{~mm})\end{array}$ & $\begin{array}{c}r_{i} \\
(\mathrm{~mm})\end{array}$ & $\begin{array}{c}\omega_{0} \\
(\mathrm{~mm})\end{array}$ \\
\hline SHS $100 \times 100 \times 5$ & $1 \mathrm{~B}$ & - & 1200 & 1000 & 333.3 & 100.0 & 100.0 & 4.63 & 2.10 & 0.022 \\
\hline SHS $120 \times 120 \times 5$ & $2 \mathrm{~B}$ & - & 1400 & 1200 & 400.0 & 120.1 & 120.2 & 4.60 & 5.80 & 0.120 \\
\hline RHS $150 \times 100 \times 6$ & $3 B$ & Major & 1800 & 1600 & 533.3 & 150.0 & 100.0 & 5.82 & 7.02 & 0.041 \\
\hline RHS $150 \times 100 \times 8$ & $4 \mathrm{~B}$ & Minor & 1800 & 1600 & 533.3 & 100.0 & 150.1 & 7.70 & 9.60 & 0.065 \\
\hline SHS $150 \times 150 \times 8$ & $5 \mathrm{~B}$ & - & 1800 & 1600 & 533.3 & 150.1 & 150.1 & 8.00 & 11.10 & 0.069 \\
\hline
\end{tabular}

Table 8 Summary of test results for beams.

\begin{tabular}{|c|c|c|c|c|c|c|}
\hline Cross-section & Specimen ID & Axis of bending & $\begin{array}{l}\text { Ultimate moment } M_{u} \\
\qquad(\mathrm{kNm})\end{array}$ & $M_{u} / M_{e l}$ & $M_{u} / M_{p l}$ & Rotation Capacity $R$ \\
\hline SHS $100 \times 100 \times 5$ & $1 \mathrm{~B}$ & - & 39.1 & 1.57 & 1.32 & $>13.75$ \\
\hline SHS $120 \times 120 \times 5$ & $2 \mathrm{~B}$ & - & 42.5 & 1.42 & 1.21 & 12.60 \\
\hline RHS $150 \times 100 \times 6$ & $3 \mathrm{~B}$ & Major & 70.9 & 1.51 & 1.23 & $>19.24$ \\
\hline RHS $150 \times 100 \times 8$ & $4 B$ & Minor & 59.7 & 1.27 & 1.07 & $>11.52$ \\
\hline SHS $150 \times 150 \times 8$ & $5 B$ & - & 165.9 & 1.34 & 1.12 & 7.96 \\
\hline
\end{tabular}


Table 9 Measured dimensions of uniaxial bending plus compression specimens.

\begin{tabular}{|c|c|c|c|c|c|c|c|c|}
\hline Cross-section & Specimen ID & $\begin{array}{c}e_{0} \\
(\mathrm{~mm})\end{array}$ & $\begin{array}{c}L \\
(\mathrm{~mm})\end{array}$ & $\begin{array}{c}H \\
(\mathrm{~mm})\end{array}$ & $\begin{array}{c}B \\
(\mathrm{~mm})\end{array}$ & $\begin{array}{c}t \\
(\mathrm{~mm})\end{array}$ & $\begin{array}{c}r_{i} \\
(\mathrm{~mm})\end{array}$ & $\begin{array}{c}\omega_{0} \\
(\mathrm{~mm})\end{array}$ \\
\hline \multirow{4}{*}{ SHS $100 \times 100 \times 5$} & $1 \mathrm{C}$ & 17.9 & 350.0 & 100.0 & 99.9 & 4.65 & 2.08 & 0.060 \\
\hline & $1 \mathrm{D}$ & 25.8 & 350.0 & 100.0 & 100.0 & 4.70 & 2.20 & 0.060 \\
\hline & $1 \mathrm{E}$ & 52.9 & 350.0 & 100.0 & 100.0 & 4.66 & 2.14 & 0.060 \\
\hline & $1 \mathrm{~F}$ & 120.0 & 350.0 & 100.0 & 100.1 & 4.66 & 2.15 & 0.060 \\
\hline \multirow{4}{*}{ SHS $120 \times 120 \times 5$} & $2 \mathrm{C}$ & 10.0 & 399.9 & 120.2 & 120.1 & 4.65 & 5.79 & 0.071 \\
\hline & $2 \mathrm{D}$ & 38.0 & 400.0 & 120.0 & 120.1 & 4.61 & 5.70 & 0.071 \\
\hline & $2 \mathrm{E}$ & 68.0 & 400.0 & 120.0 & 120.0 & 4.61 & 5.81 & 0.071 \\
\hline & $2 \mathrm{~F}$ & 120.0 & 399.8 & 120.0 & 120.1 & 4.59 & 5.75 & 0.071 \\
\hline \multirow{4}{*}{ RHS $150 \times 100 \times 6$} & $3 \mathrm{C}$ & 44.8 & 350.1 & 150.1 & 100.1 & 5.85 & 7.00 & 0.069 \\
\hline & $3 \mathrm{D}$ & 64.1 & 449.8 & 150.4 & 100.0 & 5.85 & 7.05 & 0.069 \\
\hline & $3 \mathrm{E}$ & 92.4 & 450.1 & 150.1 & 99.9 & 5.82 & 7.01 & 0.069 \\
\hline & $3 \mathrm{~F}$ & 128.4 & 450.0 & 150.2 & 100.0 & 5.90 & 7.05 & 0.069 \\
\hline \multirow{4}{*}{ RHS $150 \times 100 \times 8$} & $4 \mathrm{C}$ & 19.9 & 450.0 & 150.1 & 100.0 & 7.73 & 9.61 & 0.041 \\
\hline & $4 \mathrm{D}$ & 51.6 & 450.2 & 150.1 & 100.1 & 7.70 & 9.64 & 0.041 \\
\hline & $4 \mathrm{E}$ & 74.9 & 450.0 & 150.1 & 100.0 & 7.71 & 9.70 & 0.041 \\
\hline & $4 \mathrm{~F}$ & 140.0 & 450.1 & 150.0 & 100.0 & 7.68 & 9.60 & 0.041 \\
\hline \multirow{4}{*}{ SHS $150 \times 150 \times 8$} & $5 \mathrm{C}$ & 29.5 & 449.8 & 150.2 & 150.0 & 8.00 & 11.10 & 0.025 \\
\hline & $5 \mathrm{D}$ & 51.6 & 450.0 & 150.1 & 150.0 & 7.99 & 11.15 & 0.025 \\
\hline & $5 \mathrm{E}$ & 84.2 & 450.0 & 150.0 & 150.0 & 8.02 & 11.15 & 0.025 \\
\hline & $5 \mathrm{~F}$ & 116.4 & 450.1 & 150.0 & 150.0 & 8.04 & 11.17 & 0.025 \\
\hline
\end{tabular}


Table 10 Summary of uniaxial bending plus compression test results.

\begin{tabular}{|c|c|c|c|c|c|c|}
\hline Cross-section & Specimen ID & $\begin{array}{c}e_{0} \\
(\mathrm{~mm})\end{array}$ & $\begin{array}{c}N_{u} \\
(\mathrm{kN})\end{array}$ & $\begin{array}{c}e^{\prime} \\
(\mathrm{mm})\end{array}$ & $\begin{array}{c}M_{u} \\
(\mathrm{kNm})\end{array}$ & $\begin{array}{c}\phi_{u} \\
(\operatorname{deg})\end{array}$ \\
\hline \multirow{4}{*}{ SHS $100 \times 100 \times 5$} & $1 \mathrm{C}$ & 17.9 & 743.5 & 4.4 & 16.6 & 1.61 \\
\hline & $1 \mathrm{D}$ & 25.8 & 622.2 & 4.8 & 19.0 & 1.72 \\
\hline & $1 \mathrm{E}$ & 52.9 & 472.7 & 6.1 & 27.9 & 2.07 \\
\hline & $1 \mathrm{~F}^{\mathrm{b}}$ & 120.0 & - & - & - & - \\
\hline \multirow{4}{*}{ SHS $120 \times 120 \times 5$} & $2 \mathrm{C}$ & 10.0 & 793.5 & 2.6 & 10.0 & 0.98 \\
\hline & $2 \mathrm{D}$ & 38.0 & 550.0 & 2.8 & 22.4 & 1.24 \\
\hline & $2 \mathrm{E}$ & 68.0 & 424.0 & 3.0 & 30.1 & 1.55 \\
\hline & $2 \mathrm{~F}^{\mathrm{a}}$ & 120.0 & 296.1 & 3.2 & 36.5 & - \\
\hline \multirow{4}{*}{ RHS $150 \times 100 \times 6$} & $3 \mathrm{C}$ & 44.8 & 825.2 & 6.2 & 42.1 & 2.04 \\
\hline & $3 \mathrm{D}$ & 64.1 & 685.3 & 7.2 & 48.9 & 2.60 \\
\hline & $3 \mathrm{E}$ & 92.4 & 575.7 & 7.4 & 57.5 & 2.60 \\
\hline & $3 \mathrm{~F}$ & 128.4 & 473.4 & 8.8 & 64.9 & 3.16 \\
\hline \multirow{4}{*}{ RHS $150 \times 100 \times 8$} & $4 \mathrm{C}$ & 19.9 & 1173.8 & 9.5 & 34.5 & 3.06 \\
\hline & $4 \mathrm{D}$ & 51.6 & 800.1 & 12.4 & 51.2 & 3.93 \\
\hline & $4 \mathrm{E}$ & 75.0 & 626.9 & 13.2 & 55.3 & 4.66 \\
\hline & $4 \mathrm{~F}^{\mathrm{b}}$ & 140.0 & - & - & - & - \\
\hline \multirow{4}{*}{ SHS $150 \times 150 \times 8$} & $5 \mathrm{C}$ & 29.5 & 2186.7 & 7.2 & 80.3 & 2.40 \\
\hline & $5 \mathrm{D}$ & 51.6 & 1814.9 & 7.2 & 106.7 & 2.76 \\
\hline & $5 \mathrm{E}$ & 84.2 & 1403.6 & 7.3 & 128.4 & 3.19 \\
\hline & $5 \mathrm{~F}^{\mathrm{b}}$ & 116.4 & 1186.9 & $>3.4$ & 142.2 & - \\
\hline
\end{tabular}
a. Fracture of welded end plate occurred prior to specimen failure.
b. No rotation data was obtained.
c. Test was interrupted near peak load. 
Table 11 Measured dimensions of biaxial bending plus compression specimens.

\begin{tabular}{cccccccccc}
\hline Cross-section & Specimen ID & $\begin{array}{c}e_{0 y} \\
(\mathrm{~mm})\end{array}$ & $\begin{array}{c}e_{0 z} \\
(\mathrm{~mm})\end{array}$ & $\begin{array}{c}L \\
(\mathrm{~mm})\end{array}$ & $\begin{array}{c}H \\
(\mathrm{~mm})\end{array}$ & $\begin{array}{c}B \\
(\mathrm{~mm})\end{array}$ & $\begin{array}{c}t \\
(\mathrm{~mm})\end{array}$ & $\begin{array}{c}r_{i} \\
(\mathrm{~mm})\end{array}$ & $\begin{array}{c}\omega_{0} \\
(\mathrm{~mm})\end{array}$ \\
\hline & $1 \mathrm{G}$ & 20.0 & 20.0 & 350.0 & 120.1 & 120.0 & 4.60 & 5.75 & 0.030 \\
SHS 100×100×5 & $1 \mathrm{H}$ & 23.0 & 43.0 & 349.9 & 120.1 & 120.1 & 4.70 & 5.78 & 0.030 \\
& $1 \mathrm{I}$ & 20.0 & 60.0 & 350.0 & 120.0 & 120.1 & 4.65 & 5.80 & 0.030 \\
& $1 \mathrm{~J}$ & 23.0 & 78.0 & 350.0 & 120.0 & 120.1 & 4.65 & 5.75 & 0.030 \\
\hline
\end{tabular}

Table 12 Summary of biaxial bending plus compression test results.

\begin{tabular}{|c|c|c|c|c|c|c|c|c|c|c|}
\hline Cross-section & Specimen ID & $\begin{array}{c}e_{0 y} \\
(\mathrm{~mm})\end{array}$ & $\begin{array}{c}e_{0 z} \\
(\mathrm{~mm})\end{array}$ & $\begin{array}{c}N_{u} \\
(\mathrm{kN})\end{array}$ & $\begin{array}{c}e_{y}^{\prime} \\
(\mathrm{mm})\end{array}$ & $\begin{array}{c}e_{z}^{\prime} \\
(\mathrm{mm})\end{array}$ & $\begin{array}{c}M_{u y} \\
(\mathrm{kNm})\end{array}$ & $\begin{array}{c}M_{u z} \\
(\mathrm{kNm})\end{array}$ & $\begin{array}{c}\phi_{u y} \\
(\mathrm{deg})\end{array}$ & $\begin{array}{c}\phi_{u z} \\
(\operatorname{deg})\end{array}$ \\
\hline \multirow{4}{*}{ SHS $100 \times 100 \times 5$} & $1 \mathrm{G}$ & 20.0 & 20.0 & 633.1 & 3.1 & 3.1 & 14.6 & 14.6 & 1.48 & 1.48 \\
\hline & $1 \mathrm{H}$ & 23.0 & 43.0 & 484.3 & 2.8 & 3.8 & 12.5 & 22.7 & 0.96 & 1.95 \\
\hline & $1 \mathrm{I}$ & 20.0 & 60.0 & 428.1 & 2.3 & 4.1 & 9.5 & 27.4 & 0.92 & 2.38 \\
\hline & $1 \mathrm{~J}$ & 23.0 & 78.0 & 363.2 & 2.3 & 4.2 & 9.2 & 29.9 & 0.82 & 2.53 \\
\hline
\end{tabular}




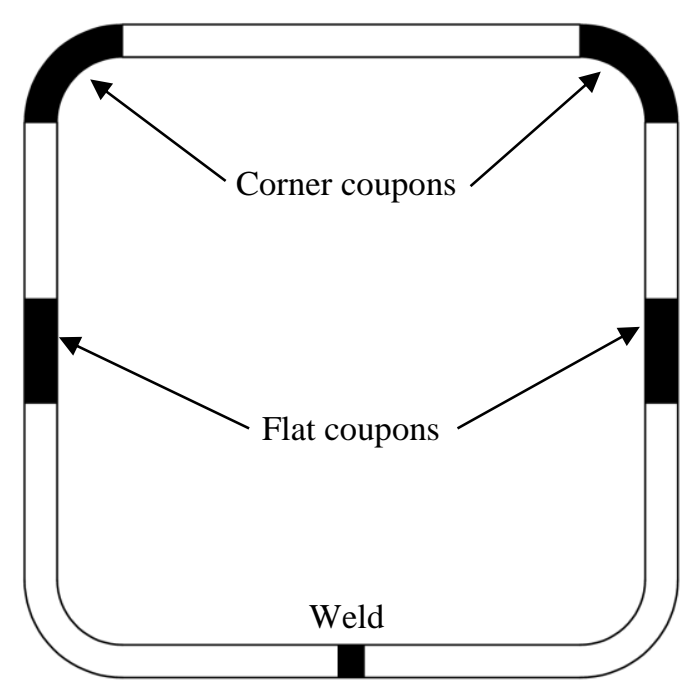

Fig. 1. Locations of coupons in the cross-section.

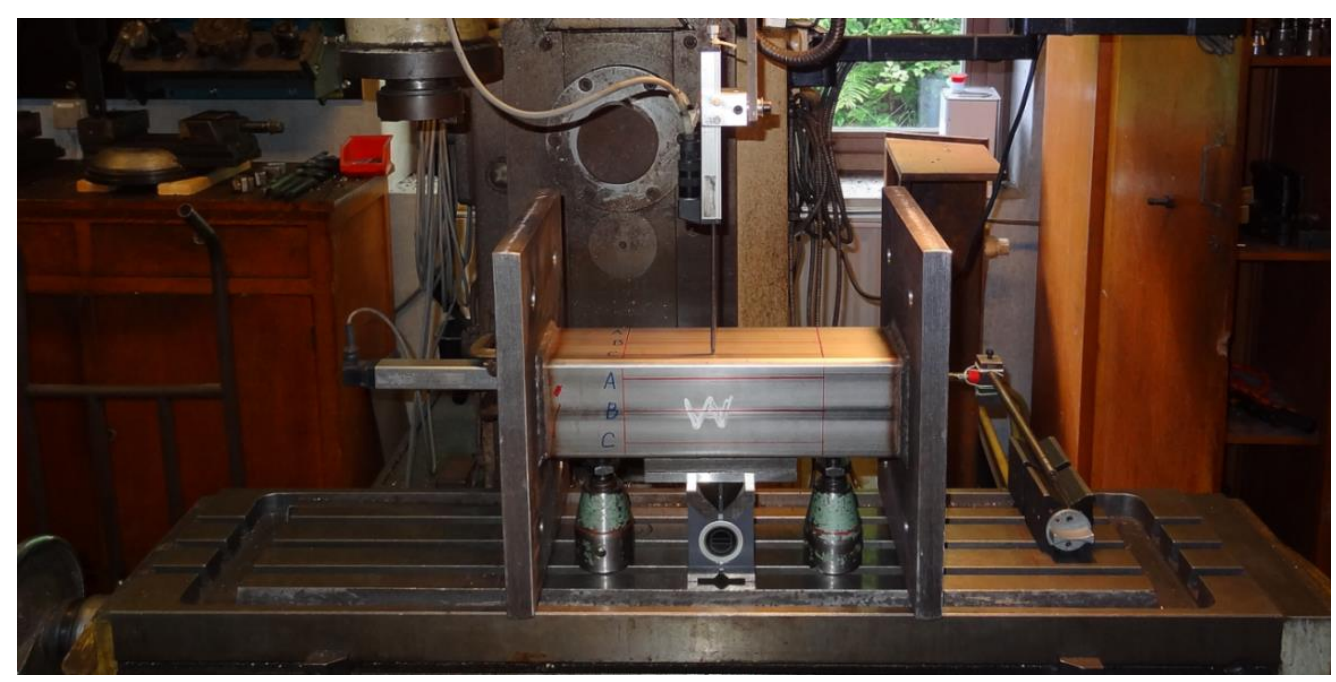

Fig. 2. Test setup for imperfection measurements.

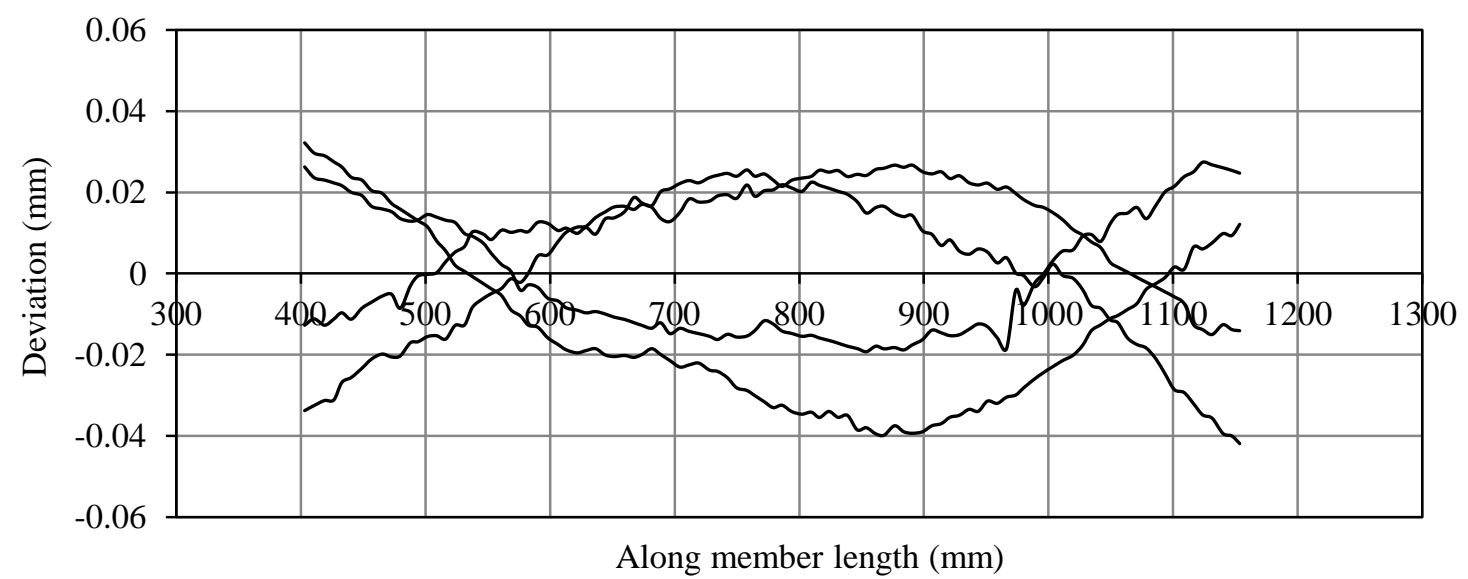

Fig. 3. Typical measured imperfection distributions, shown for specimen RHS $150 \times 100 \times 6-3 B$. 


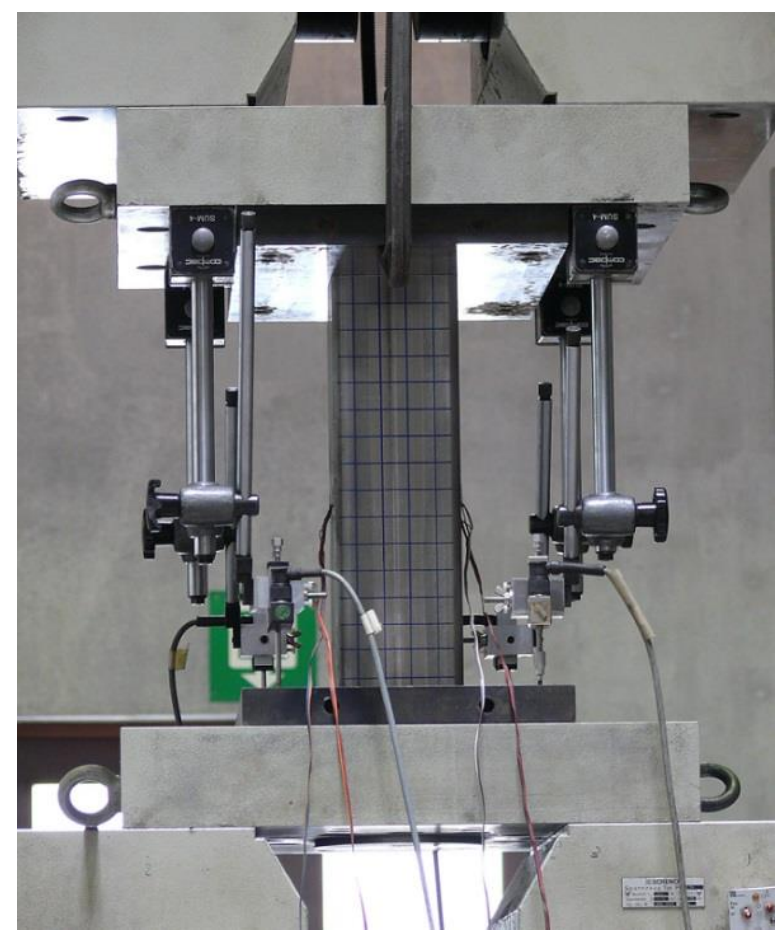

Fig. 4. Stub column test setup.

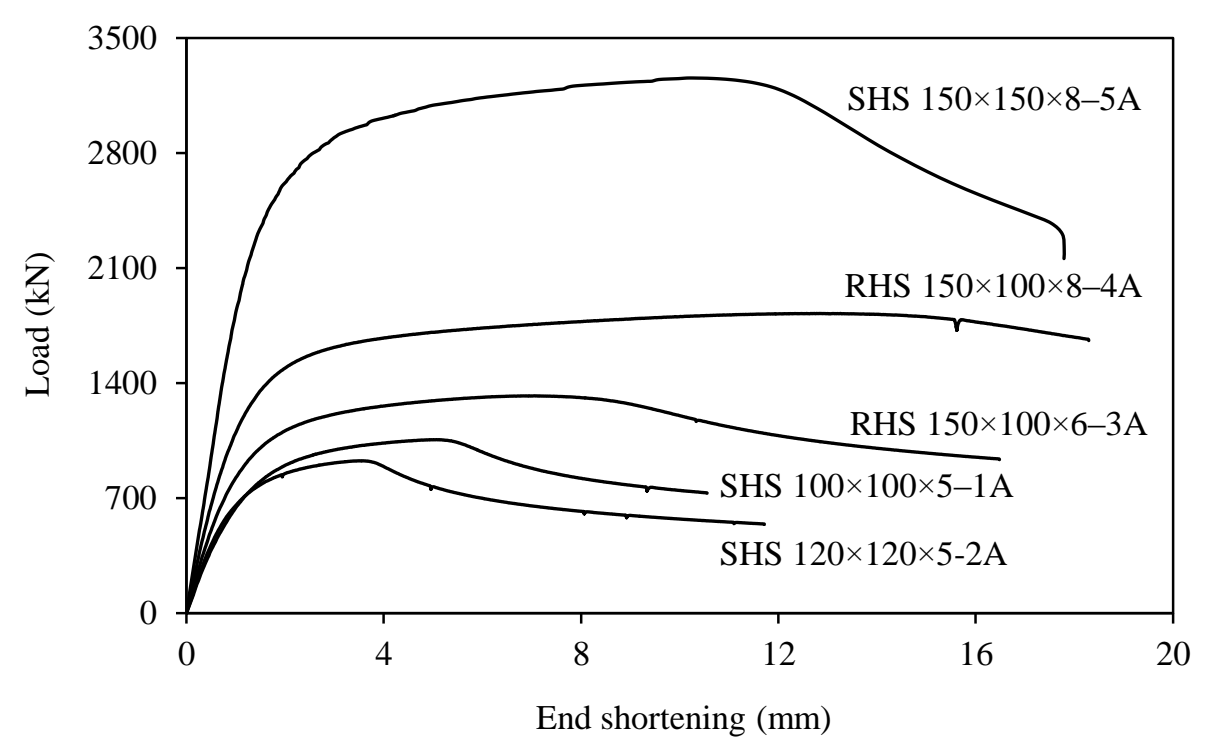

Fig. 5. Load-end shortening curves for stub column tests. 


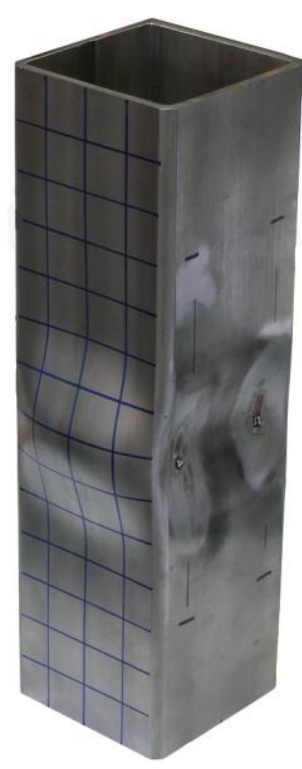

Fig. 6. Stub column failure mode of specimen SHS $100 \times 100 \times 5-1 \mathrm{~A}$.

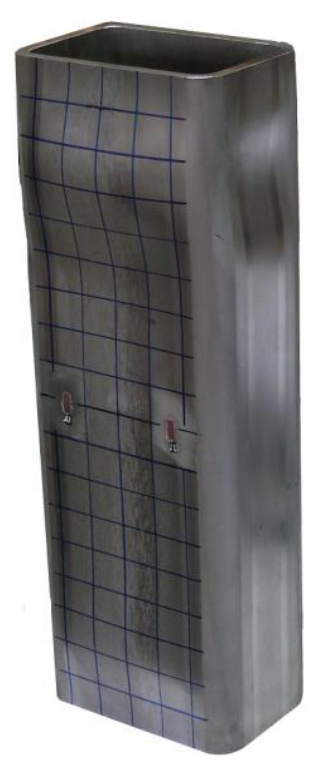

Fig. 7. Stub column failure mode of specimen RHS $150 \times 100 \times 6-3 \mathrm{~A}$.

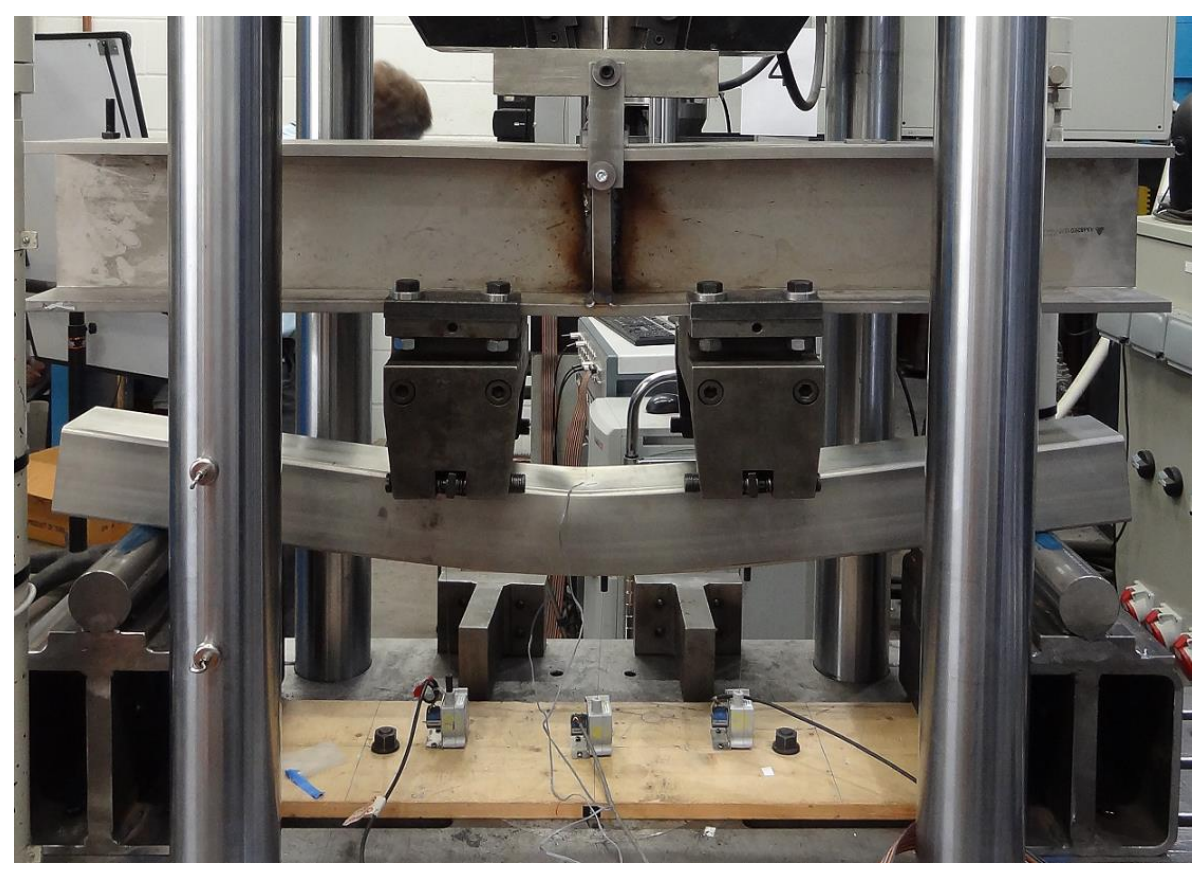

Fig. 8. Four-point bending test setup. 


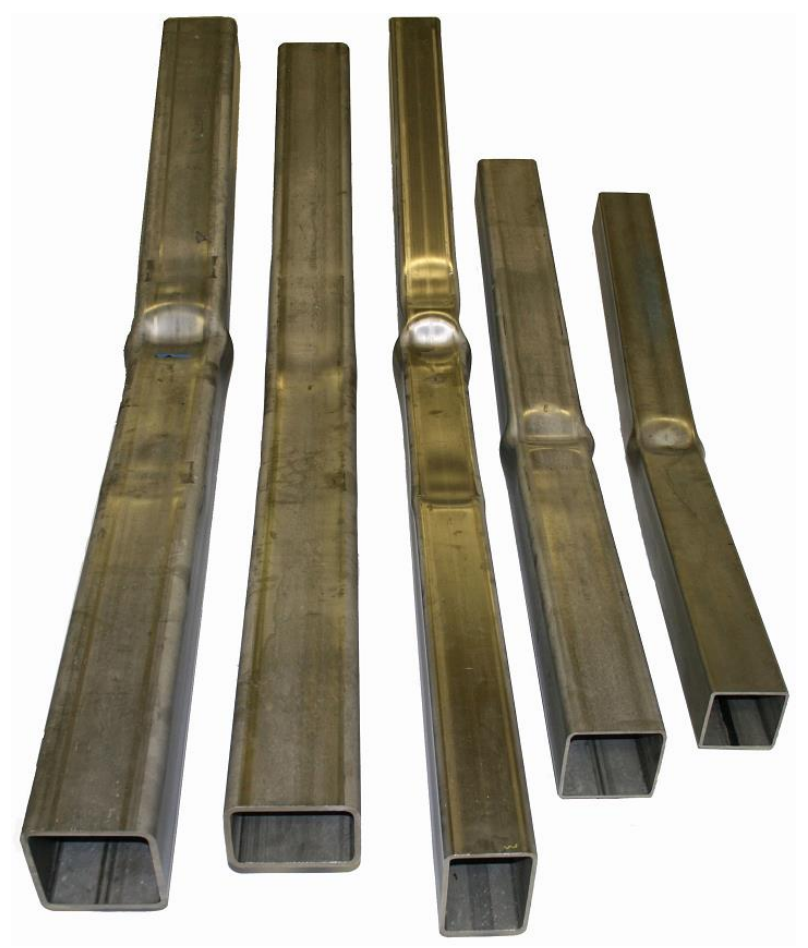

Fig. 9. Four-point bending failure modes.

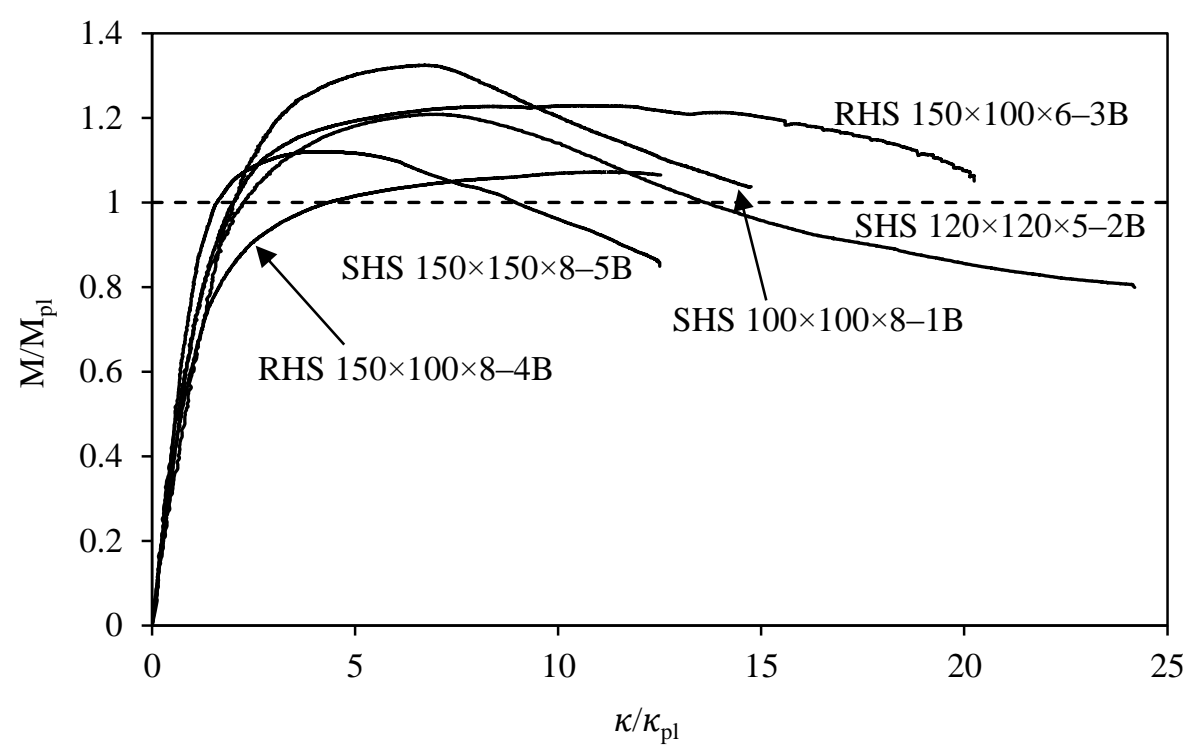

Fig. 10. Normalised moment-curvature curves for four-point bending tests. 


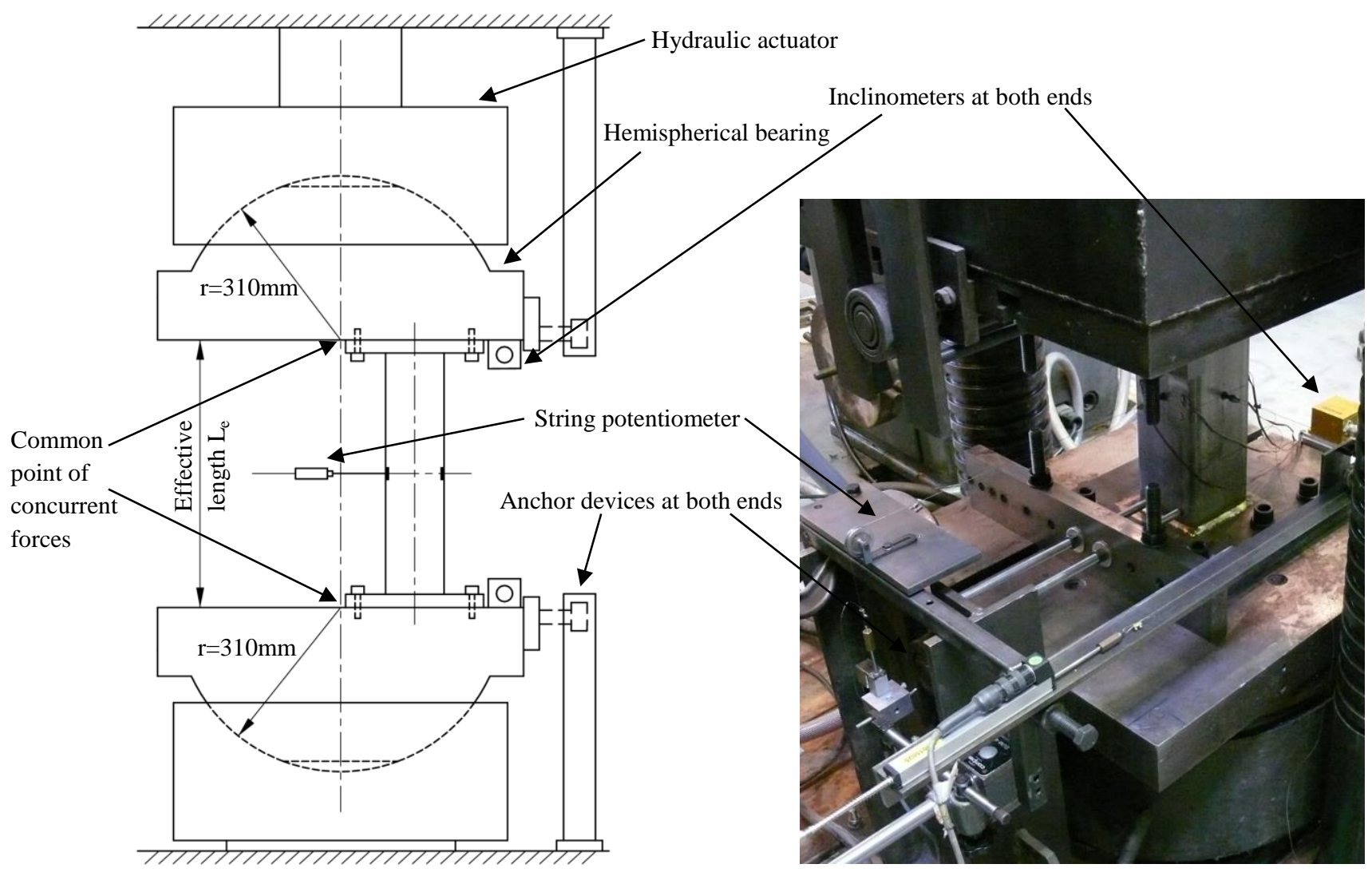

Fig. 11(a). Schematic diagram of the test setup.

Fig. 11(b). Experimental setup.

Fig. 11. Combined loading test configuration. 


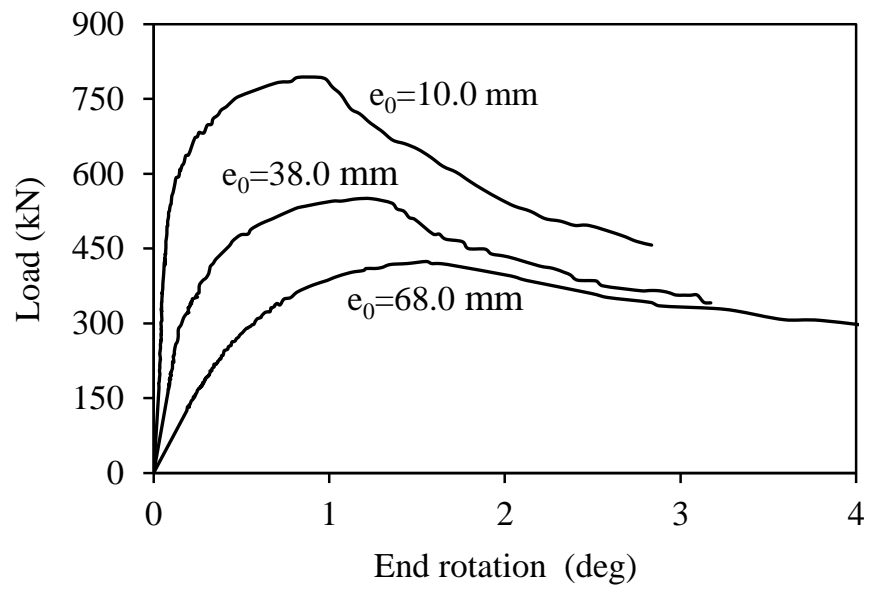

Fig. 12(a). Test curves for SHS $100 \times 100 \times 5$ (Specimens: 1C to $1 \mathrm{E}$ )

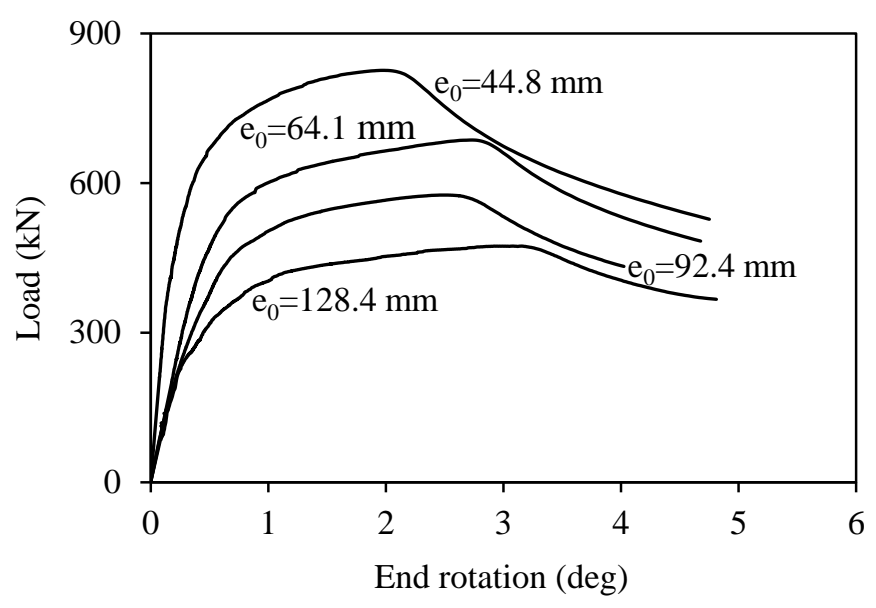

Fig. 12(c). Test curves for RHS $150 \times 100 \times 6$ (Specimens: $3 \mathrm{C}$ to $3 \mathrm{~F}$ ).

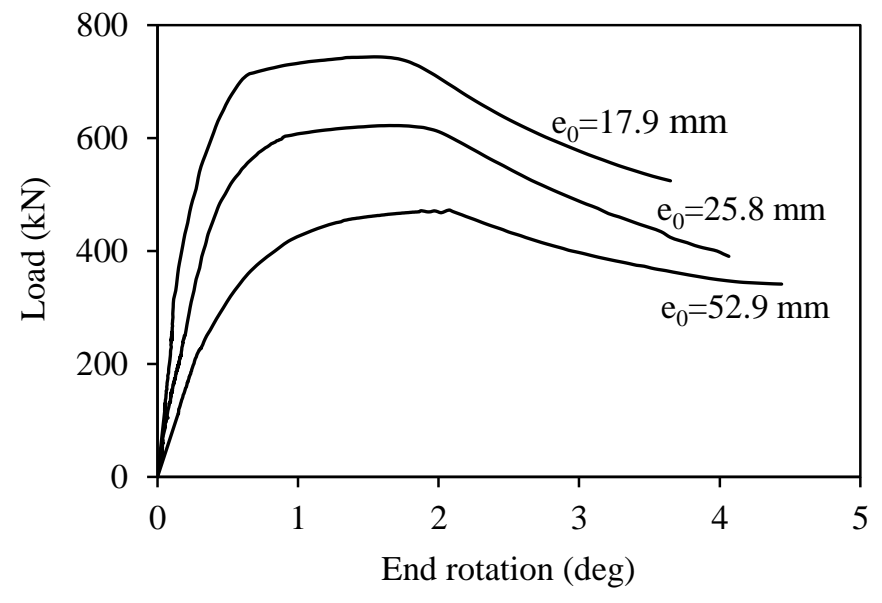

Fig. 12(b). Test curves for SHS $120 \times 120 \times 5$ (Specimens: $2 \mathrm{C}$ to $2 \mathrm{E}$ )

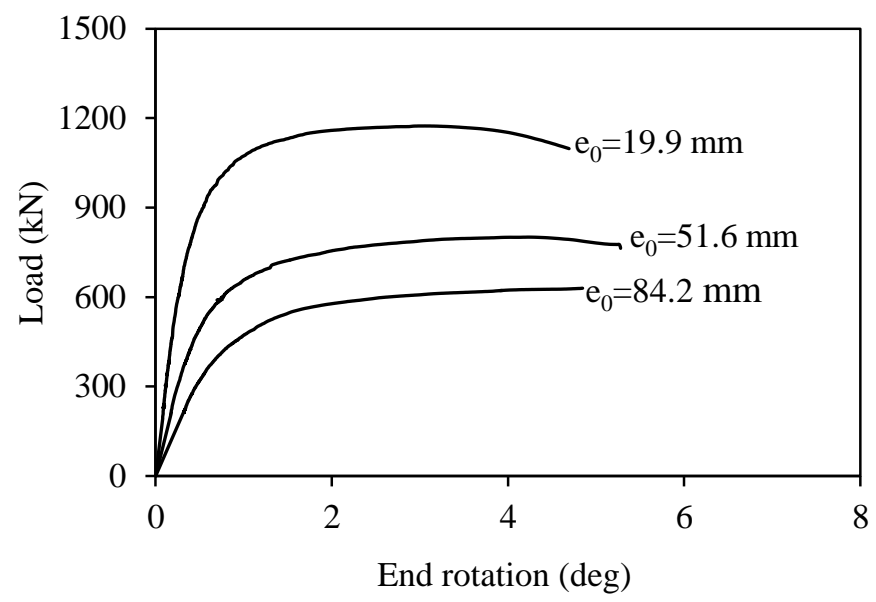

Fig. 12(d). Test curves for RHS $150 \times 100 \times 8$ (Specimens: 4C to $4 \mathrm{E}$ ).

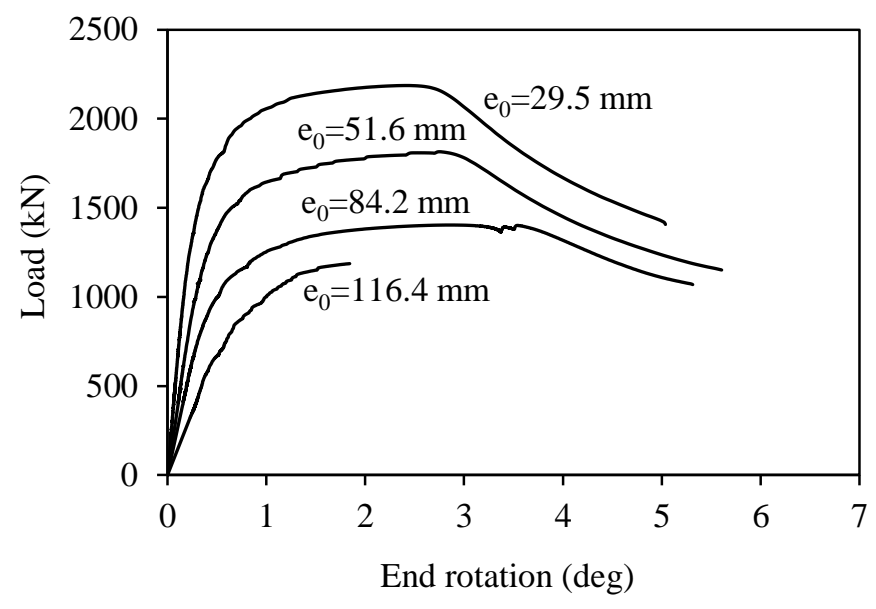

Fig. 12(e). Test curves for SHS $150 \times 150 \times 8$ (Specimens: $5 \mathrm{C}$ to $5 \mathrm{~F}$ ).

Fig. 12. Load-end rotation curves for uniaxial bending plus compression tests. 


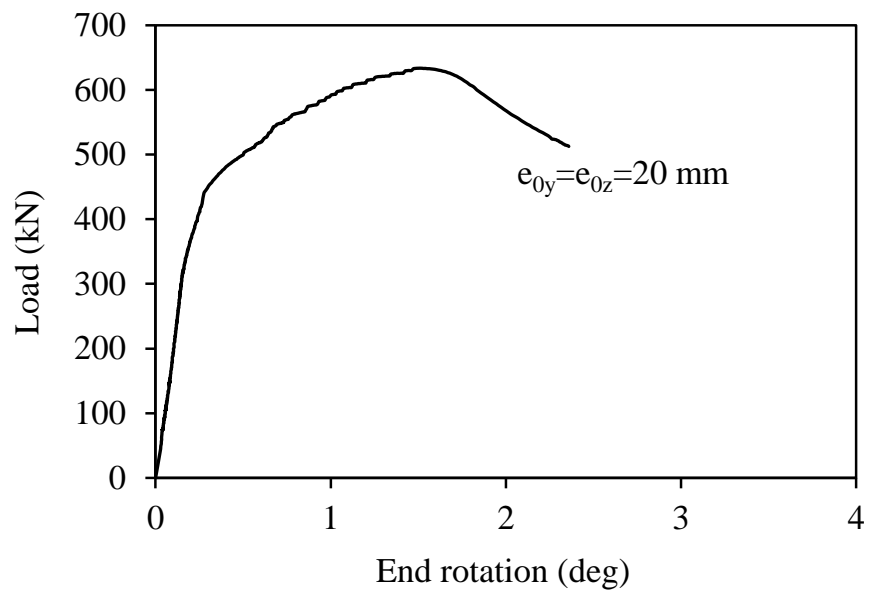

Fig. 13(a). Test curves for specimen SHS $100 \times 100 \times 5-1 G$

$$
\left(\mathrm{e}_{0 \mathrm{y}}=\mathrm{e}_{0 \mathrm{z}}=20 \mathrm{~mm}\right) \text {. }
$$

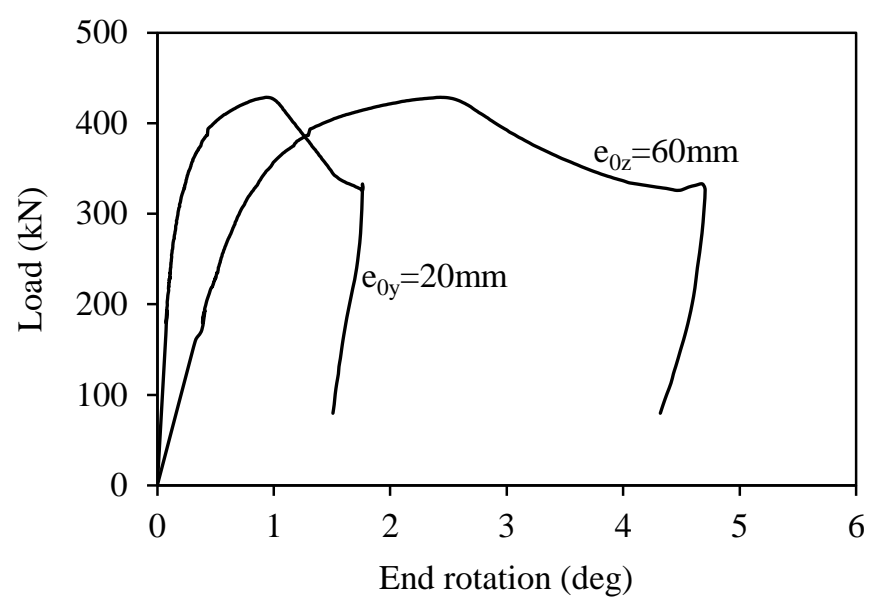

Fig. 13(c). Test curves for specimen SHS $100 \times 100 \times 5-1 \mathrm{I}$ $\left(\mathrm{e}_{0 \mathrm{y}}=20 \mathrm{~mm}, \mathrm{e}_{0 \mathrm{z}}=60 \mathrm{~mm}\right)$.

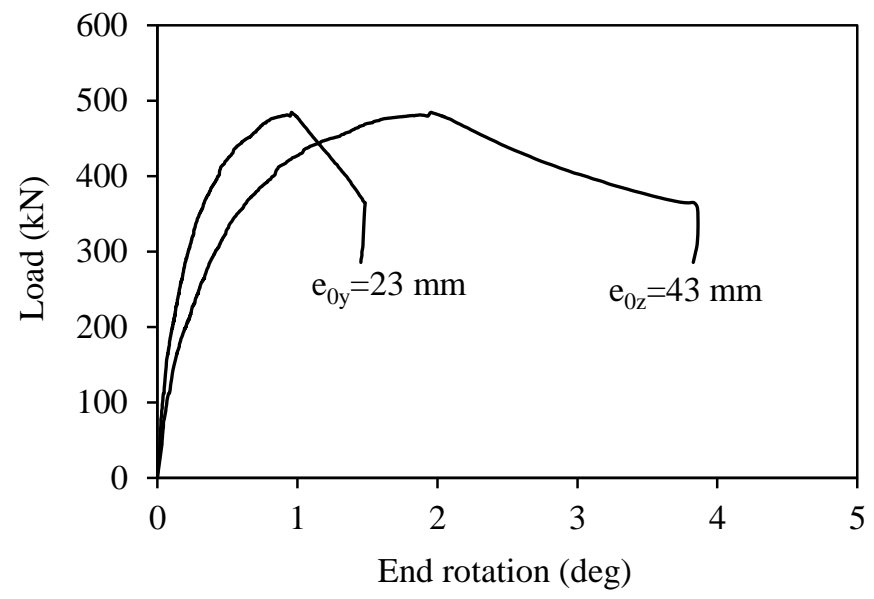

Fig. 13(b). Test curves for specimen SHS $100 \times 100 \times 5-1 \mathrm{H}$ $\left(\mathrm{e}_{0 \mathrm{y}}=23 \mathrm{~mm}, \mathrm{e}_{0 \mathrm{z}}=43 \mathrm{~mm}\right)$.

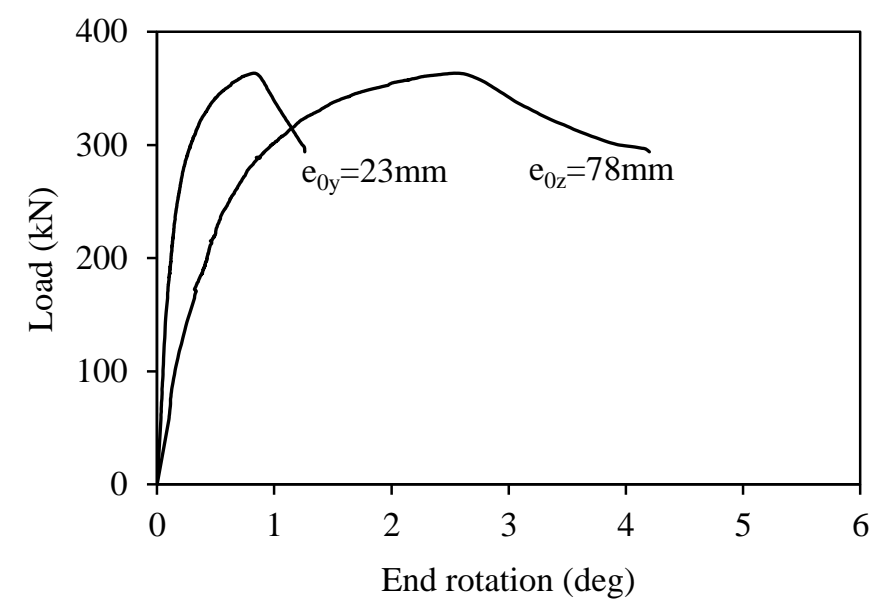

Fig. 13(d). Test curves for specimen SHS $100 \times 100 \times 5-1 \mathrm{~J}$ $\left(\mathrm{e}_{0 \mathrm{y}}=23 \mathrm{~mm}, \mathrm{e}_{0 \mathrm{z}}=78 \mathrm{~mm}\right)$.

Fig. 13. Load-end rotation curves for biaxial bending plus compression tests. 


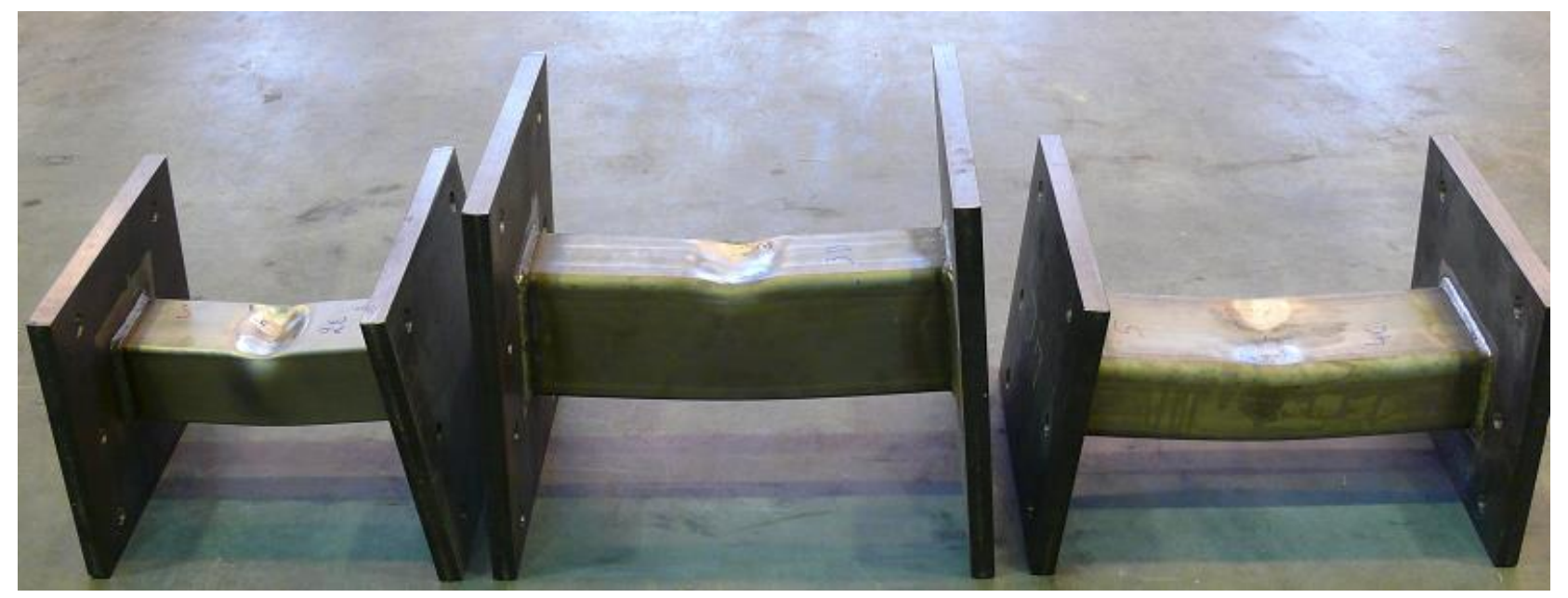

Fig. 14. Typical failure modes for uniaxial bending plus compression tests (from left to right: SHS $100 \times 100 \times 5$ 1 D, RHS $150 \times 100 \times 6-3$ D, RHS $150 \times 100 \times 8-4$ D).

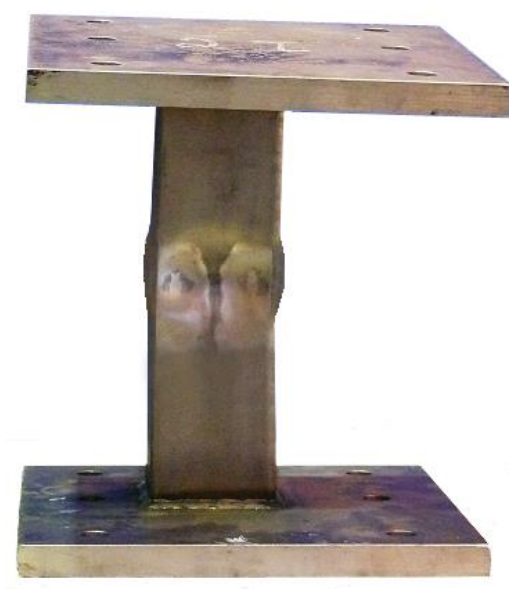

Fig. 15. Typical failure mode from biaxial bending plus compression tests $\left(\mathrm{SHS} 100 \times 100 \times 5-1 \mathrm{I}: \mathrm{e}_{0 \mathrm{y}}=20 \mathrm{~mm}\right.$, $\left.\mathrm{e}_{0 \mathrm{z}}=60 \mathrm{~mm}\right)$. 